\title{
THE EFFECT OF PRACTICE UPON VISUALIZING AND UPON THE REPRODUCTION OF VISUAL IMPRESSIONS.
}

\author{
W. S. FOSTER. \\ From the Educational Laboratory, Cornell Universuty.
}

\section{Summary.}

Real objects, pictures, and nonsense-drawings were shown to three observers for moderate times (10 to 60 sec.). Exact reproduction by drawing, sometimes supplemented by wrtten description, was then required. Stress was laid upon introspection of the obserring and reproducing consciousness. Each observer deroted to the work about forty hours, distributed through ten weeks.

Ability to reproduce increased with practice, although the increase was rapid at first and slow later. The greatest gain of final over initial ability was $44 \%$; the least, $6 \%$.

The chief reasons for the practice-improvement were:

1. Confidence and "doing one's best" replaced discouragenent and "giving up."

2. Familiarity with material lessened the difficulty.

3. The observers learned where and how to distribute attention effectively.

4. More efficient methods of work were adopted. 'Tricks of counting, naming, grouping, etc., were discovered and used.

5. Regular and definite procedure replaced hap-hazard, unorganzed procedure.

In no case did practice increase the ability or even the tendency to visualize. The best reproducer of visual impressions was the poorest visualizer, and relied almost wholly upon verbal cues for recall.

Our results show that the ability gained is very sperific.

\section{The Problem.}

The problem, as we first roughly stated it to ourselves was: What is the value of such a formal training in "visualizing" as is sometimes recommended for school exercises? By the 
use of carefully graded material and properly arranged series, we proposed to measure the observers' initial and final ability to represent to themselves in image, impressions recently given in sensation. By requiring detailed introspections we hoped, if possible, to discover the factors or processes concerned in observation and reproduction, together with their relative importance. This knowledge should then enable us to say why observers differ in ability and in capacity for training this ability, and to determine the dependence of ability upon kind of material, amount of practice, etc. Such knowledge should also enable us to judge from the similarity or identity of factors concerned, in how far practiceeffects are transferable, $i$. $e$, how far they are of value for work with other kinds of material and under other conditions. It will thus be seen that we aimed to supplement Professor Whipple's study of the effect of practice in visual apprehension as conducted in this laboratory (13) by lengthening the duration of exposure and by laying stress upon the visualizing process itself. Kuhlmann (14) also made an analytic study of consciousness during the recall of visually presented forms, but his problem, unlike ours, was primarily a qualitative, rather than a quantitative one.

\section{The Observers.}

The observers were Dr. I. R. Geissler, $(G)$, instructor in psychology ; Dr. Helen M. Clarke $(C)$, late fellow in psychology; Miss Alma DeVries ( $V)$, a graduate student in psychology. All were thoroughly trained in introspection and familiar with laboratory methods. None, with the exception of $G$., who had taken part in Professor Whipple's apprehension tests three years before (13), had had previous training in work at all similar to ours. Moreover, in $G$ 's case, material and experimental conditions of this experiment were so different from the former one, that he himself denies that he could discover any advantage gained from previous training. Results confirm this opinion.

Before the experiment proper, all three observers were 
tested as to ideational type by the use of Bett's Questionary (4), and by questions as to verbal imagery and its use. $G$ has exceptionally poor, sketchy images in all, sense departments, except kinesthetic, where his images are good. He reports that his visual and auditory images are rare, and that he does most of his work in kinesthetic, especially kinesthetic-verbal terms, and ordinarily in sensory rather than imaginal terms. $V$ has complete and vivid images in all departments, but reports that she tends to use visual images whenever they will serve. She uses few word images. $C$ is of mixed type, and has good images in all modalities except audition. She reports that her mental processes are predominantly of the visual and kinesthetic-verbal type.

\section{The Material.}

Six kinds of material were used:

1. Ink dots on $1.5 \times 1.5$ in. white paper. They were arranged at haphazard upon the intersections of imaginary lines 0.25 in. apart. The dots varied in number from 7 to 14 ; average, 10. After exposure the observer was required to reproduce them at the proper intersections on 0.25 in. cross-section paper.

2. Irregular closed polygons formed by lines joining dots arranged as in 1 . The number of lines was 8 to 10 ; average, 9. Reproduction on cross-section paper as in 1 .

3. Nonsense figures drawn on white cardboard in India. ink. These were composed of lines $1 / 4$ in. broad. The lines were of three lengths $-3 / 8$ in., $3 / 4$ in., and $1.5 \mathrm{in.;}$ and of four kinds-straight, curved, dotted, and wavy. They were arranged by chance, end to end, at angles of $0^{\circ}, 45^{\circ}$, and $90^{\circ}$ to each other, so as to form a fairly compact, connected group. Number of lines, 8 to 12, average, 10 .

4. Figures drawn with a fountain pen on cardboard of the same size as in 3 . They were intended to suggest objects such as trees, birds, airships, etc., but always contained too few or too many lines for a good representation. Average 
number of lines, 12. In actual work the observers seldom (only nine times in some two hundred) got a meaning for the figure as a whole. This material, therefore, although labelled suggestive, is classed with the above three kinds as nonsense material.

5. Drawings and photographs of real objects, such as houses, churches, mills, ete., the main lines of which were at once apparent.

6. Objects found in the educational laboratory and museum, such as tools, small models, and bits of apparatus, with not too many details.

As this description indicates, the material was so selected or constructed as not to give an advantage to the observer who excelled merely as a draughtsman, but so that the report of each observer might serve directly as an index of the completeness and fidelity of his memory.

\section{Method.}

The observation periods were always in the morning, and as far as possible, at regular hours. Three to five hours per week were spent by each observer $(O)$, one hour being the most spent in any single day by any observer. The experimenter $(E)$ sat at a table opposite $O$, gave a 'ready' signal, exposed the card by placing it face up on the table before $O$, and kept the time by a stop-watch. In general, the exposure was regulated (by a test series on others than the regular $O$ 's) so that it should be short enough to encourage maximal effort and attention, and yet long enough so that $O$ might 'run over' the whole in detail and 'see the parts clearly' at least once. The time for all nonsense material was 10 sec., and repeated exposures of this length were made up to the first faultless reproduction. For sense-material, the times varied from 20 to $60 \mathrm{sec}$, according to the complexity and difficulty of the material presented.

$O$ was instructed as follows: "Look at the stimulus attentively. Try to 'blaze it into your mind' so that you can draw an exact copy from memory. Make your drawing as accurate, 
detailed, and complete a copy of the original as you can. What you cannot possibly draw or indicate, you may describe in words,"

The order of experiments was this: A series composed of one each of the different kinds of material, in the order $1,2,3,4,5,6$, (dots, polygon, nonsense-figure, suggestive, picture, object) was given and then a new series began. About thirty such series were given to each $O$. ( $V$ missed five series through absence from town, but was given the full number of dots in order to have a basis for comparison with the other $O$ 's.) Although within each kind of material there were differences in degree of difficulty, (e.g., 7, 9, 10. 14 dots), the average degree of difficulty was kept constant for each group of five successive series. Detailed introspections were called for, and changes of method or attitude, were always noted as soon as they appeared.

No scoring was done until the whole experiment was finished. Then $E$ examined all the drawings and reports and marked in percentages the proporticn of the stimulus correctly drawn after the first exposure, and in the case of nonsense material, also counted the number of reproductions necessary for the first faultless reproduction. Of course, in the case of the more complex sense-material, the scoring could be only approximate, but the nonsense material easily lent itself to more accurate marking. Here, since the figures were arrangements of a few elements, it was easy to define and evaluate the kinds of mistakes, as for example. omission or insertion of elements, mistakes in the kind of element in a given position, its direction, ete. Arbitrary rules were followed which rendered the scoring of the several $O$ 's strictly comparable.

The experiment naturally falls into three periods:- $\mathrm{I}$, the initial period, composed of the first five series, characterised by small percentages and a large number of reptitions necessary for faultless reproductions, together with large nean variations; II, the practice period embraeing the next 
twenty series (except in case of $\mathrm{V}$ where the number of series is 15 except for dots), characterised by a gradual increase in percentages and a decreasing number of repetitions; and III, the final period of five series, which serves as a measure of ability at the close of the experiment.

Table I shows the average percentages and average number of repetitions for each period and for each $O$.

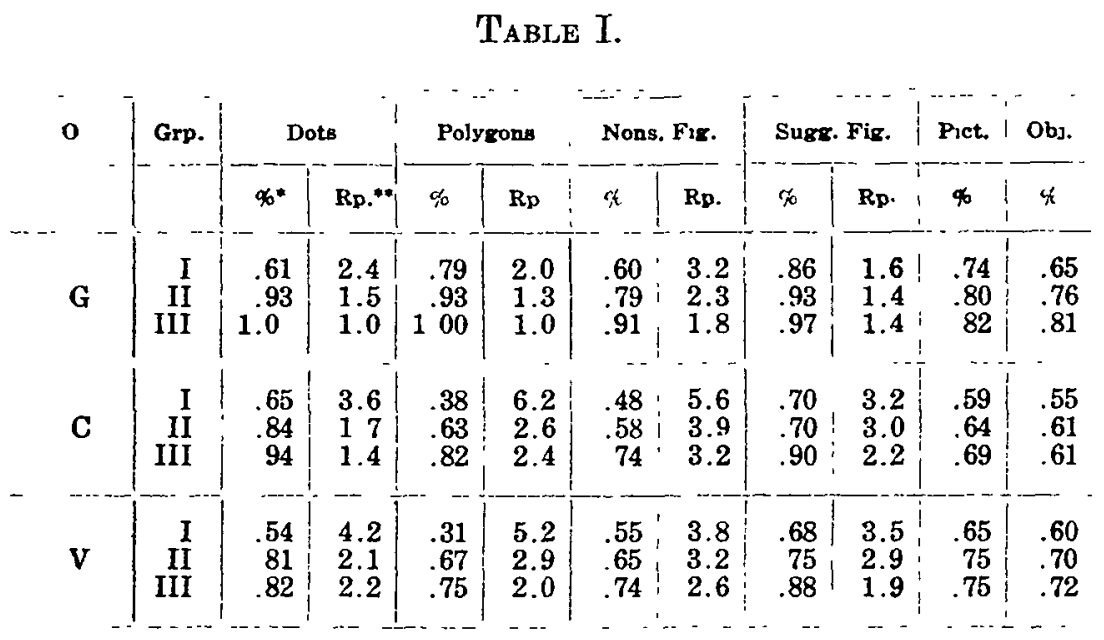

$\%=\%$ correct on first reproduction.

** $R \mathbf{p}$. =number of repetitions required for first faultless reproduction.

\section{Results.}

1. That practice increased the $O$ 's efficiency in reproduction is evident at once from the table. The percentages for all $O ' s$ and for all kinds of material are considerably higher in the final than in the initial period. Gain in efficiency ranges from $6 \%$ to $44 \%$; average $22 \%$, and in the case of nonsense material, practice saves from .2 to 3.8 repetitions.

2. A striking fact is that gains in ability are so large at . first and so small later in the experiment. The gains of II over I, (that is, in the first half of the experiment) vary from $5 \%$ to $36 \%$, average $15 \%$, and from .2 to 3.6 repetitions, while 
those of III over II, (last half of the experiment) range only from 0 to $19 \%$, average $7 \%$, and from-1 to 1 in saving of repetitions. The reasons for such a distribution appear clearly in the introspective reports of the $O$ 's.

At first $O$ is confused and uncertain; at a loss to know how to work, hesitating, discouraged. In Period I we find common to all $O$ 's such reports as: "The material is strange, unfamiliar, crazy." "I did not know what to do," "I didn't know how to work," "I was confused," "I was disturbed," "Attention skipped from one part to another, was caught by certain details and disregarded others," "I did not know what to attend to until I discovered what kind of mistakes I was making," "I learned only gradually how much time I had and how to distribute it," "It was hard to split up the drawing into groups without getting confused," "I felt that I simply could not do it."

Moreover, at first, in drawing, the $O$ 's were inclined to indicate somewhat roughly the general aspects of the figure, instead of being careful to give each line a correct direction and length and so to produce a copy correct in detail.

By the end of Period I, however, many of these difficulties were partially overcome. By this time the material was familiar; the $O$ 's "knew what sort of stuff was coming." They had seen similar figures before, knew in many cases the elements of which the figures were built, and were no longer distracted or confused by novel conditions. They narrowed attention to essentials. They knew, too, what was essential and what was likely to be forgotten. They adopted a fairly definite method of procedure. They directed attention to parts in a regular order, knew how much time they had, distributed it properly; discovered and used tricks of grouping, counting and naming kinds, lengths, directions, ete. When material was presented they were 'set' definitely to meet the situation in a given way. They no longer "gave it up" or failed to do their best because of a feeling of discouragement or helplessness. 
On the other hand, during Periods 11 and III, the method of work and the attitude changed relatively little, and few additional tricks were discovered. 'L'he improvement here is due in general to a development of the uid, rather than to the discovery of new methods.

3. Table I also shows that gains witn sense-material are relatively small; with nonsense material, relatively great. The average final nonsense gain is $28 \%$; the average final sense gain, 10\%. The explanation of this fact is threefold.

First, since nonsense material was repeated up to the first faultless reproduction all favoring factors of practice had so much the more chance to show their effects.

Secondly, the nonsense material is somewhat less difficult because within each form of it certain elements are continually repeated in different arrangement. The elements of sense-material are not so easy to determine. Although perhaps we unay speak of tree, door, window, square, screw, etc., as elements, they are not constant from picture to picture, and they are not so often repeated as are the elements of nonsense material.

Thirdly, the introspective reports show that nonsense material, by its very nature, offers a greater chance for tricks of counting, naming of definite directions, etc., and lends itself more readly to a constant, orderly method of work. $O$ 's report, for instance, "I group the dots in geometrical forms, lines, triangles, etc.," "I imagine the dots and polrgons placed upon cross-section paper as I look at them," "I count the dots and lines," "I name directions and length," "I count imaginary squares," "I note in verbal terms "lines meet 3 from left, etc." "There is a regular space-time order which my eyes nearly always follow, left upper corner, across, down, across, up." With sense material the $O$ 's find less chance for such helps. They attribate gains here to more general factors, such as gain of confidence, and knowledge of how to distribute time and attention. 
4. The $O$ 's differ considerably in initial and final ability. See Table II.

TABLE II.

\begin{tabular}{|c|c|c|c|c|c|}
\hline \multirow{2}{*}{ OBSERVER } & & \multicolumn{2}{|c|}{ NONSENSE MATERIAL } & \multicolumn{2}{|c|}{ SENSE MATERIAL } \\
\hline & i & Initial Av. & Final Av & Intial Av. & Final Av. \\
\hline$--\quad-$ & - - - , - & & & & \\
\hline$\underset{\mathrm{C}}{\mathrm{G}}$ & 1 & $\begin{array}{l}.72 \\
.55\end{array}$ & $\begin{array}{r}97 \\
85\end{array}$ & $\begin{array}{l}.70 \\
.57\end{array}$ & $\begin{array}{r}82 \\
.65\end{array}$ \\
\hline V & ' & 52 & 80 & 63 & 74 \\
\hline
\end{tabular}

The explanation of these individual differences is neither easy, simple, nor certain, but facts may be mentioned which have an important bearing.

We judge the temperament of the $O$ 's to be of considerable importance, especially in its bearing upon the results in the initial series. $G$, whose percentages are highest, is by nature calm, steady, and unexcitable. Even at the beginning of the experiment his work was methodical and persistent. He is, moreover, an intensive worker, easily narrows attention to the matter in hand, and is not disturbed by conversation or noise. $V$. and $C$ are not such intensive workers. Both of them, and $C$ especially, were much confused and disturbed by the new material and conditions and were much more easily discouraged than was $G$.

Another and even more important difference between $G$ and the other $O$ 's was the type of imagery prominent in consciousness, while working. During exposure $G$ moves his eyes slowly and in a constant order over the card or object, attending to his visual and kinesthetic complexes, and at the same time maintaining an almost continuous internal speech. He groups and counts parts, names directions, parts, lengths, positions, and notes in abbreviated verbal form many significant points about content and arrangement. $\mathrm{He}$ is under a steady muscular strain. In drawing, he reports: "Eyes 
and attention follow the same order as in observing," "The movements seem almost to shoot off of themselves from some faint kinesthetic image (eye, throat, hand,') "Practically never a visual image," "Muscular strains gradually letting down as drawing progresses."

$C$ and $V$ attend during the exposure chiefly to the vis'ol aspects of the stimulus. They follow over the picture in a rather definite order, grouping elements into various forms (usually without the form being named). $C$ sometimes makes verbal notes; $V$ rarely does so. $V$ reports tension; $C$ is more passive. Both report that the drawings are to a great extent copies of visual memory-images, or at least are preceded by, "touched off by," such images. $\nabla$ believed that she did better" work when words came naturally, but found voluntary effort to name difficult and disturbing, and quickly gave it up. Both report that they have at times 'visual images of the whole stimulus,' but think that such recall is useful rather for correction of the drawing when once made than for construction. $V$ says: "If I want to draw an object actually before me, I have to attend to details one at a time. So in drawing from memory, I follow the images of details or parts in constructing and depend upon my image of the whole as a check upon whether the general proportions are correct are not."

5. Contrary to expectation, no $O$ reports any increased ability to visualize, or any tendency to visualize more because of our sort of practice. The work of observation or reproduction may be surrogated, transferred to a given sensedepartment, according to the $O$ 's ideational type. Such surrogation may even be advantageous. Here e.g., in the reproduction of visual impressions, $G$, the best observer, is the one who visualizes least, and $\nabla$, ordinarily visual, reports a slight tendency to verbalize more.

\section{Conclusions.}

How, now, shall we answer our original question of the value of formal training in visualizing and in reproducing visual impressions? 
We have found that practice such as ours does increase ability to reproduce our sort of material. We see, however, that this increased ability is dependent upon the particular material, time, instructions, and other conditions of the experiment, upon familiarity with these conditions, and upon confidence based on the familiarity. Practice, in other words, is specific. Practice with one set of conditions is valuable in a new set, only in proportion as the second set of conditions contain identical ability-conditioning factors. Some tricks, e.g., gained in practice with dot-figures are valueless in the work with other kinds of nonsense material or in work with sense material. That training in these experiments has made the $O$ 's noticeably better observers or memorizers in general, or given them any habits of observing closelv or reporting correctly, or furnished any ability to meet better any situations generally met with, neither we nor the $O$ 's themselves believe.

It appears, moreover, that little ability is gained by continuing practice beyond a certain relatively short time.

Specific practice is demanded for best results and becomes quickly effective. It seems, therefore, as if the value of formal training of our lind had been greatly overestimated. However, our experiments were made upon adults who were already trained in habits of attentive observation, and we have no right or wish to extend our conclusions in wholesale fashion. It may be that, for immature or untrained persons, practice in visual reproduction might possess a general value that was not discovered under our conditions.

\section{Rejerences.}

(1) G. AlBIEx. Der Anteil der nachkonstrucrenden Tutigkett des Auges und der Apperception an dem Bchalten und der Wedergabe einfacher Formen. Zeitsch. f. exp. Padagogik, VI, 1908, p. 1-48.

(2) F. ANgell and J. Coover. General Practice Effect of Special Excrcise. Am. Journ. Psych., XVIII, 1907, p. 328.

(3) J. H. Barr. The Practice Curve. Psyeh. Rer. Mon.. Supp.l 19, 1902. 
(4) (). Betrs, Distribution and Functions of Mfental Imagery. Columbia Univ. Contributions to Education, 1909.

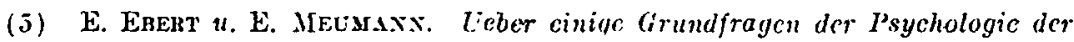
Ubungsphunomenc in Berewhe des Gciachtisses. Arch. f. d. ges. P'sych., IV, 1905 , p. Iff.

(6) G. Fhacker. On the Transference of Tramung in Alemory. Psych. Rev., MIon Suppl. 5, 1908.

(7) W JAstes. P'sychology 1, 1893, p 667 .

(8) C. Jown. Practice and its Ifffects in the Perception of lllustons. Psych. Rev., IX, 1902, p 2 Tff

(9) 19. Loustex. Cbung unel Gedachtnts. Zeits. f. exp Padagogik, III, 1906, p. 1 jlff

(10) E. Mevalaxx Torlesungen zur Einfuhtung un dhe raperimentelle Padagogil und the psycholagisehen Grundlagen, II, 1907, p. 1-7S.

(11) E. L. THonvolke AND R. S. Woodwortir. Infuence of Improvement in one Vental Function upon the Effierency of other Finctions. Psyeh. Rer., VIII, 1901. pp. 247, 384, 5.53

(12) H. J. WaTT Economy and Training of If cmory. 1909. pp. 1-4, 70-72. 91-108

(13) G. M. WhIPISE. The Effect of Practice upon the Range of Tisual Attention and of Fisual Apprehension Jour. Educ. Psych., I, 1910, p. 249tr.

(14) F. Kumluann. On the Analysis of the Ifcmory Conscionsness. Psyel. Rer., XIII, 1906, p. $310 \mathrm{fr}$. 